\title{
Simulation Analysis of Characteristics for Independent Metering Control System Based on Downstream Compensation
}

\author{
Guotai Zhang1, Jie $\mathrm{Xu}^{2}$, Jing Yang ${ }^{3}$, Kailei Liu ${ }^{4}$ \\ ${ }^{1}$ Medium Size Excavator R\&D Institute, Sany Heavy Machinery Co., Ltd., Kunshan, China \\ ${ }^{2}$ Big Size Excavator R\&D Institute, Sany Heavy Machinery Co., Ltd., Kunshan, China \\ ${ }^{3}$ School of Mechanical Engineering, Yanshan University, Qinhuangdao, China \\ ${ }^{4}$ School of Mechanical Engineering, Jiangsu University of Technology, Changzhou, China \\ Email: 15032367781@163.com
}

How to cite this paper: Zhang, G.T., Xu, J., Yang, J. and Liu, K.L. (2019) Simulation Analysis of Characteristics for Independent Metering Control System Based on Downstream Compensation. World Journal of Engineering and Technology, 7, 536-547. https://doi.org/10.4236/wjet.2019.73038

Received: July 21, 2019

Accepted: August 24, 2019

Published: August 27, 2019

Copyright (c) 2019 by author(s) and Scientific Research Publishing Inc. This work is licensed under the Creative Commons Attribution International License (CC BY 4.0)

http://creativecommons.org/licenses/by/4.0/

\begin{abstract}
Aiming at the shortcomings of the separate meter in and separate meter out hydraulic system, a new type of independent metering control system is proposed by referring to the principle of load-sensing system. The valve group unit in the system is designed, and the AMESim/Matlab cosimulation model of the component and system is established. The actuator speed control, energy consumption and anti-flow saturation characteristics of the system are discussed. The simulation result shows that the system proposed in this article can achieve better performances.
\end{abstract}

\section{Keywords}

Independent Metering Control, Pressure Compensation, Cosimulation

\section{Introduction}

Hydraulic transmission technology has the advantages of high power-mass ratio and convenient speed regulation. It has been widely used in heavy metallurgical equipment, construction machinery, aerospace and other fields. The traditional hydraulic control system (such as system controlled by three-position four-way valve) is limited by the fixed structure of the spool valve. Its valve throttles both in the meter-in and meter-out oil circuit, so there is redundant throttling loss in the system, and there is still room for improving the overall efficiency of the system. At the same time, there is a direct coupling relationship between the pressure and flow parameters in the two chambers of the actuator, and the degree of 
freedom that the system parameters can be adjusted is relatively small. In order to solve both problems, Professor Palmberg of LinköPIng University in Sweden first proposed the concept of separate meter-in and separate meter-out system in 1990 [1], that is, two or more valves are used to control the inlet and outlet of actuator respectively. At present, the research in this field mainly focuses on three aspects: system principle design [2] [3], selection of working mode of actuator [4] [5], and speed and pressure control strategy [6] [7]. At present, many scholars have studied a calculated flow feedback method (virtual dynamic flow test) [8] [9] [10]. This method owns the advantages of high response and accuracy control, but it also has shortcomings of high system design cost and less practical application.

Energy-saving has become one of the research focuses on hydraulic technology [11]. In order to promote and apply the technology of independent metering control in practical projects, from the perspective of reducing system design cost, combining the traditional principle of load-sensing system, this paper proposes a new independent metering control system principle. In the early stage, control components (integrated valve, which includes main valve and pressure compensation valve) have been calculated and simulated. In the later stage, relevant simulation studies on the speed control, energy-saving and anti-flow saturation characteristics of the system have been carried out. The above work can provide a reference for the development of this system.

\section{System Principle}

The hydraulic principle of the new independent metering control system presented in this paper is shown in Figure 1. Before introducing the principle of this system, the pressure compensation in hydraulic technology is explained as follows. The hydraulic system in construction machinery is often driven by a single pump with multiple actuators. The loads of actuator are often time-variant and

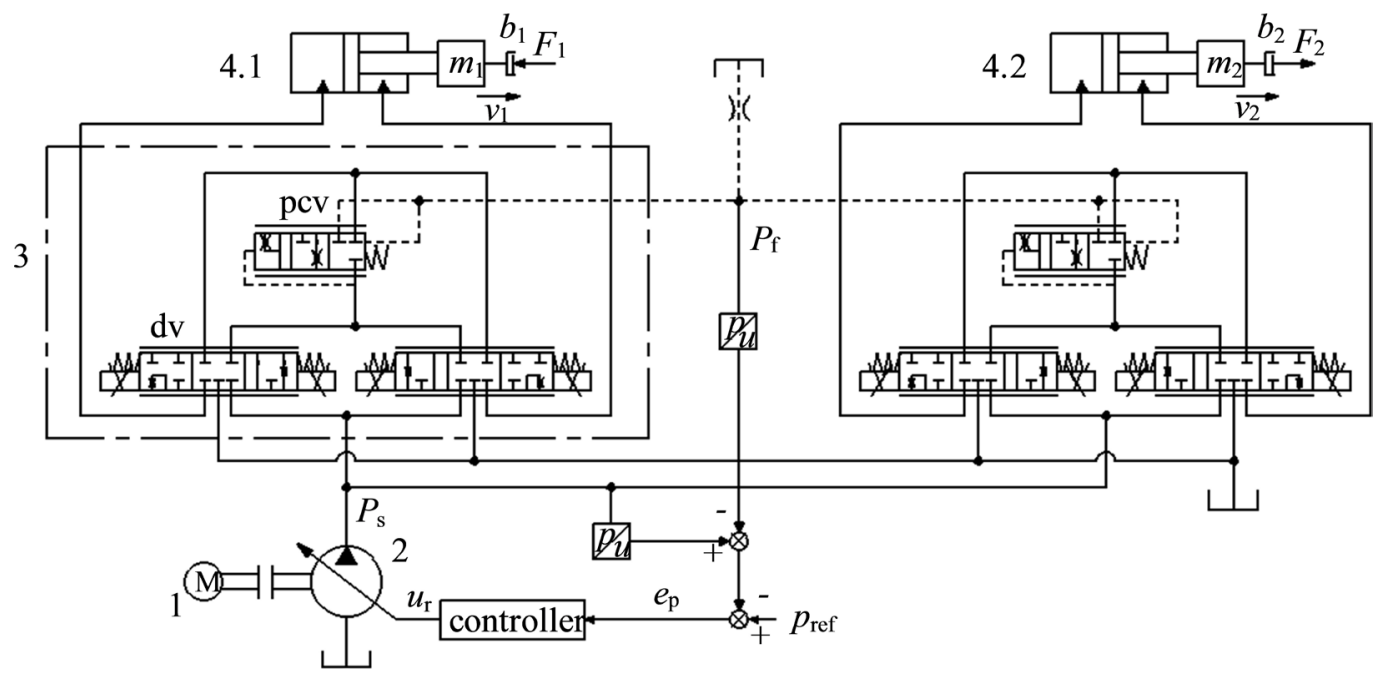

1. electric motor; 2 . variable displacement pump; 3. valve group unit; 4 . hydraulic cylinder

Figure 1. Principle of independent metering control system based on downstream compensation. 
different. Therefore, in order to maintain the speed of actuator without the influence of load changes, typical mechanical-hydraulic load-sensing system usually takes compensatory measure for pressure difference of the directional valve, such as the PVG series multi-way valve produced by Danfoss and M4 series multi-way valve produced by Bosch Rexroth. However, the load-sensing system based on above compensation principle has the disadvantages of slow control response and unstable speed regulation in terms of dynamic characteristics [12]. With the rapid development of electronic transducer technology, in the 1990s, western universities such as RWTH Aachen University began to study the electronic-hydraulic load-sensing system using electrical signals to replace mechanical and hydraulic signals earlier [13]. The pressure signal of the system is detected by pressure sensors, and the systems start to use the electronic-hydraulic proportional pump. Relevant research results show that the electronic-hydraulic load-sensing system is superior to traditional mechanical-hydraulic load-sensing system in many aspects [14] [15]. Combining the electronic-hydraulic load-sensing technology and independent metering control technology, the innovative system design is carried out and its principle is as follows. Giving the control signals of two three-position five-way proportional directional valves (dv), the two valves can be in three different working states. By switching the working position of the two directional valves, different control functions can be realized. For example, when both directional valves are in the right position, the inlet and return oil circuits of the actuator are in the throttling state, which implements the independent control of the actuator. In addition, when the left directional valve works in the right position and the right directional valve works in the left position, the hydraulic cylinder can realize differential control. The pressure compensation valve (pcv) senses the maximum load pressure of all actuators and ensures that the pressure drop of the inlet valve in each valve group unit is similar. The opening of the pressure compensation valve is determined by the difference between the maximum load pressure in the system and the load pressure of the corresponding actuator. The pressure sensors are installed at the outlet of the pump and the pressure feedback pipe to compare the actual pressure difference with given pressure margin. The displacement controller outputs corresponding electrical signal to control the electronic-hydraulic variable displacement pump to output the flow and pressure corresponding to the system requirements.

\section{Parameter Design}

The cross-sectional view of the symmetrical plane of the three-position five-way electric proportional direction valve is shown in Figure 2.

The maximum flow rate of the directional valve is set at $60 \mathrm{~L} / \mathrm{min}$. The size values of the directional valve are calculated by using the traditional design methods of hydraulic valve as shown in Table 1.

The orifice of directional valve adopts U-shaped throttle groove. The rectangular coordinate system shown in Figure 3 is established. The flow area of U-shaped 


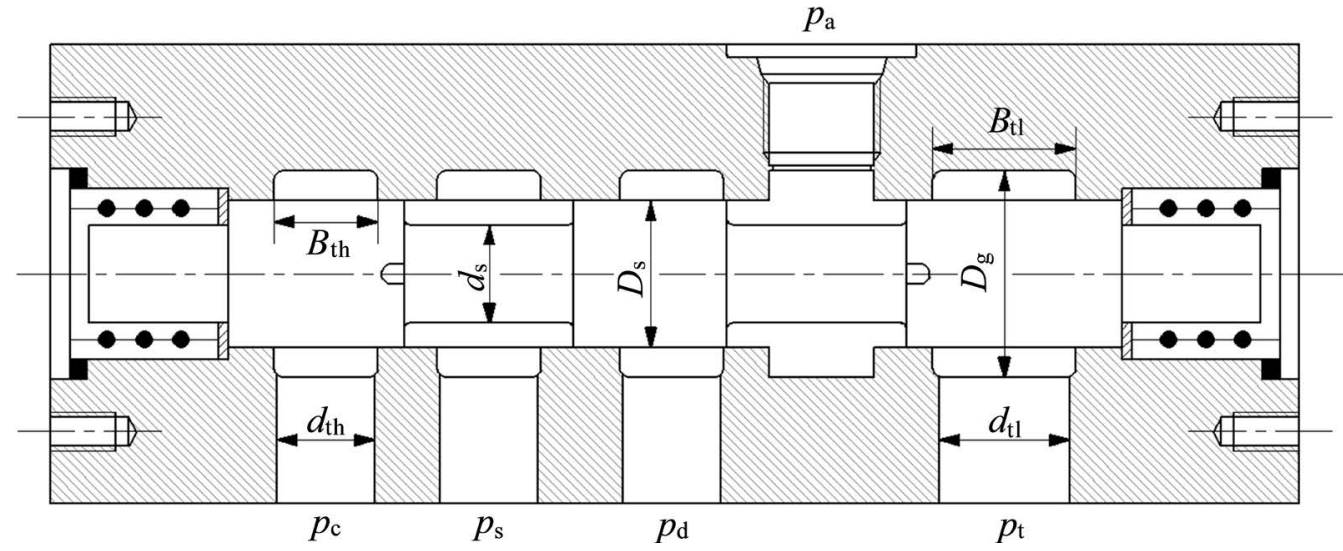

Figure 2. Structural drawing of directional valve.

Table 1. The size values of the directional valve (unit: $\mathrm{mm}$ ).

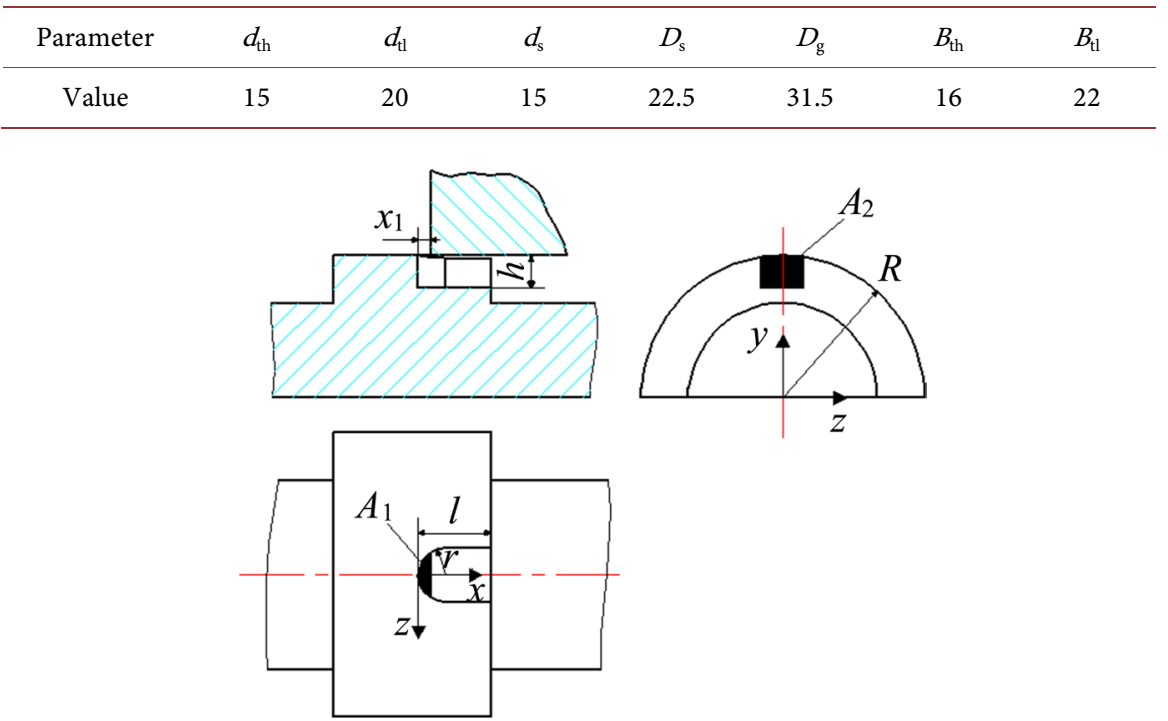

Figure 3. U-throttle groove structure.

throttle groove is replaced by two main throttle surfaces in series. The calculation formula is as follows: (1)-(3). The specific parameters are substituted as follows: groove diameter $r=1.5 \mathrm{~mm}$, groove depth $h=2.2 \mathrm{~mm}$, groove length $l=3.5$ $\mathrm{mm}$, groove number $n=4$, flow coefficient $C_{\mathrm{de}}=C_{\mathrm{d} 1}=0.61$, and $C_{\mathrm{d}}=0.72$. By using the software of MATLAB/Simulink, the relationship curve between the flow area and the opening of the valve is obtained as shown in Figure 4.

$$
\begin{aligned}
& A_{1}= \begin{cases}n \int_{0}^{x_{1}} R \cdot 2 \arcsin \frac{z}{R} \mathrm{~d} x & 0<x_{1} \leq r \\
n\left(\int_{0}^{r} R \cdot 2 \arcsin \frac{z}{R} \mathrm{~d} x+\left(x_{1}-r\right) \cdot R \cdot 2 \arcsin \frac{r}{R}\right) & r<x_{1} \leq l\end{cases} \\
& A_{2}= \begin{cases}n\left[y z+R^{2} \arcsin \frac{z}{R}-2 z(R-h)\right] & 0<x_{1} \leq r \\
n\left[r \sqrt{R^{2}-r^{2}}+R^{2} \arcsin \frac{r}{R}-2 r(R-h)\right] & r<x_{1} \leq l\end{cases}
\end{aligned}
$$




$$
A_{\mathrm{e}}=\frac{C_{\mathrm{d} 1} C_{\mathrm{d} 2} A_{1} A_{2}}{C_{\mathrm{de}} \sqrt{C_{\mathrm{d} 1}^{2} A_{1}^{2}+C_{\mathrm{d} 2}^{2} A_{2}^{2}}}
$$

The cross-sectional view of the symmetrical plane of the pressure compensation valve is shown in Figure 5.

The size values of the pressure compensation valve are shown in Table 2.

\section{Simulation Research}

\subsection{Simulation Model}

The simulation model of the system is mainly composed of three parts: valve group unit, electric proportional pump and other components (pipeline, actuator, etc.), which are modeled separately below.

The unit model of valve group includes three-position five-way electric proportional directional valve and pressure compensation valve. The simulation models are built on the software platform of AMESim and Matlab/Simulink, respectively, as shown in Figure 6 and Figure 7.

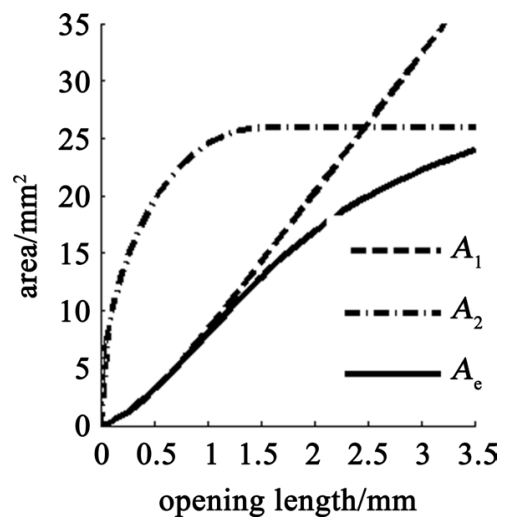

Figure 4. Flow area.

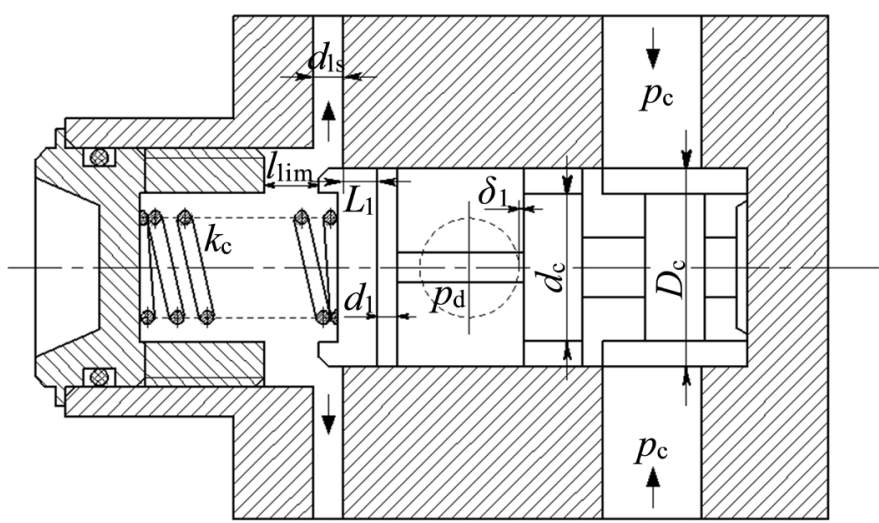

Figure 5. Structural drawing of the pressure compensation valve.

Table 2. The size values of the pressure compensation valve (unit: $\mathrm{mm}$ ).

\begin{tabular}{cccccccc}
\hline Parameter & $D_{\mathrm{c}}$ & $d_{\mathrm{c}}$ & $\delta_{1}$ & $d_{1}$ & $L_{1}$ & $1_{\text {lim }}$ & $d_{\text {ls }}$ \\
\hline Value & 20 & 14.8 & 0.5 & 2 & 3.5 & 5.5 & 3
\end{tabular}




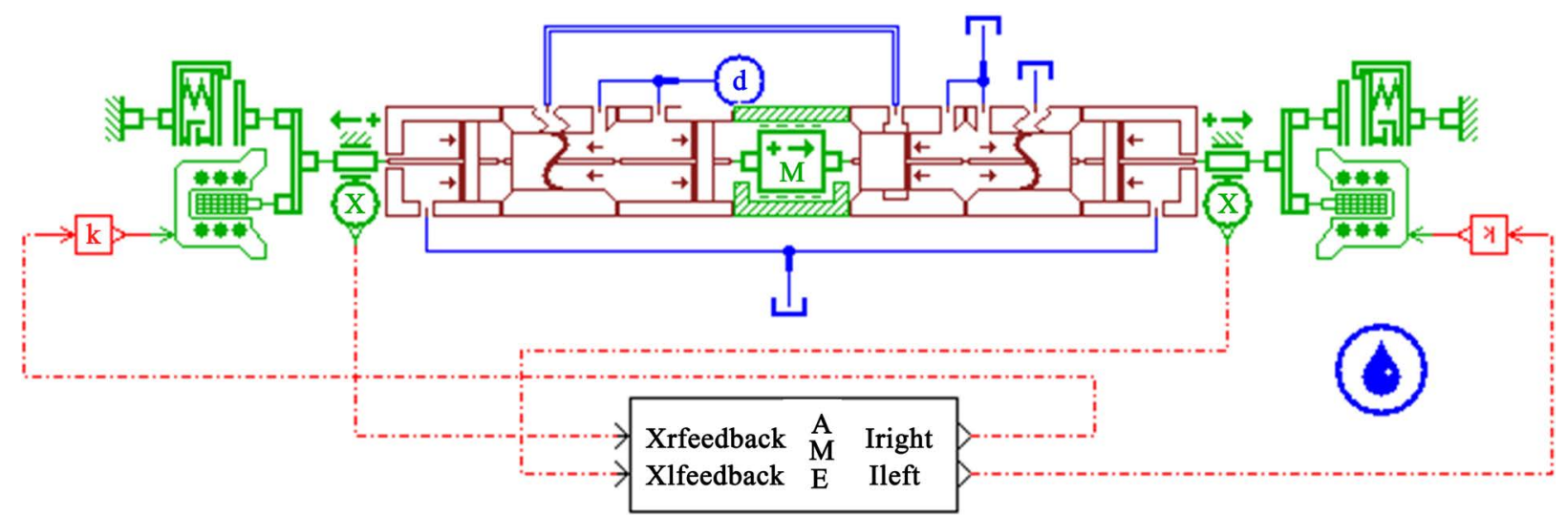

Figure 6. The mechanical-hydraulic model of the directional valve.

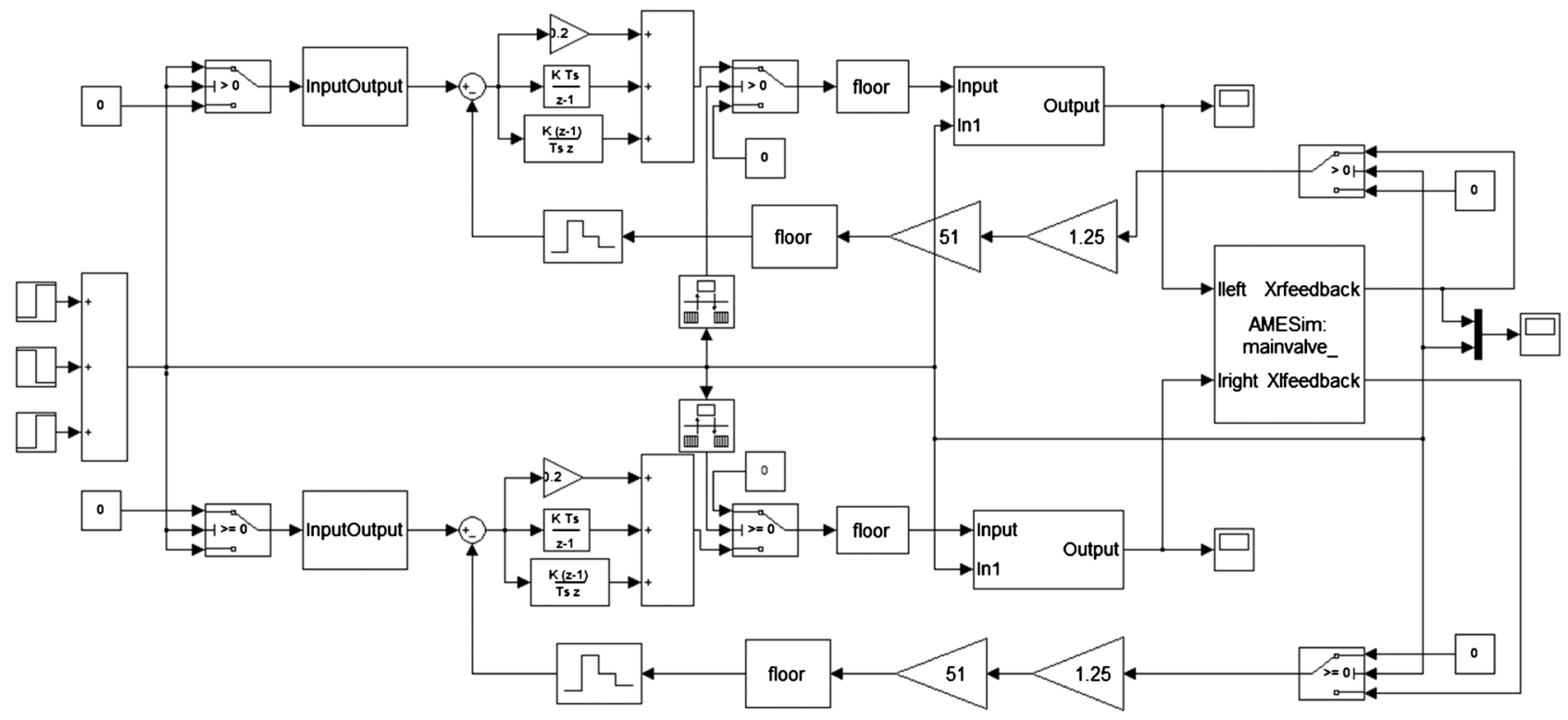

Figure 7. The control model of the directional valve.

Table 3. Simulation parameters.

\begin{tabular}{cccc}
\hline Physical meaning & Value and unit & Physical meaning & Value and unit \\
\hline Mass of spool & $0.39 \mathrm{~kg}$ & Current force gain & $187.5 \mathrm{~N} / \mathrm{A}$ \\
Viscous damped coefficient & $80 \mathrm{~N} \cdot \mathrm{s} \cdot \mathrm{m}^{-1}$ & Displacement sensor gain & $1.25 \mathrm{~V} / \mathrm{mm}$ \\
Coulomb friction & $2 \mathrm{~N}$ & Maximum stroke of spool & $4 \mathrm{~mm}$ \\
Static friction & $5 \mathrm{~N}$ & Input pressure & $1.8 \mathrm{MPa}$ \\
\hline
\end{tabular}

The partial simulation parameters in the model of the directional valve are shown in Table 3.

The A4VSO electric proportional pump produced by Bosch Rexroth Company is used as the hydraulic source of the system. The simulation model of the pump is shown in Figure 8.

The simulation parameters of the electric proportional pump model are set as shown in Table 4. 


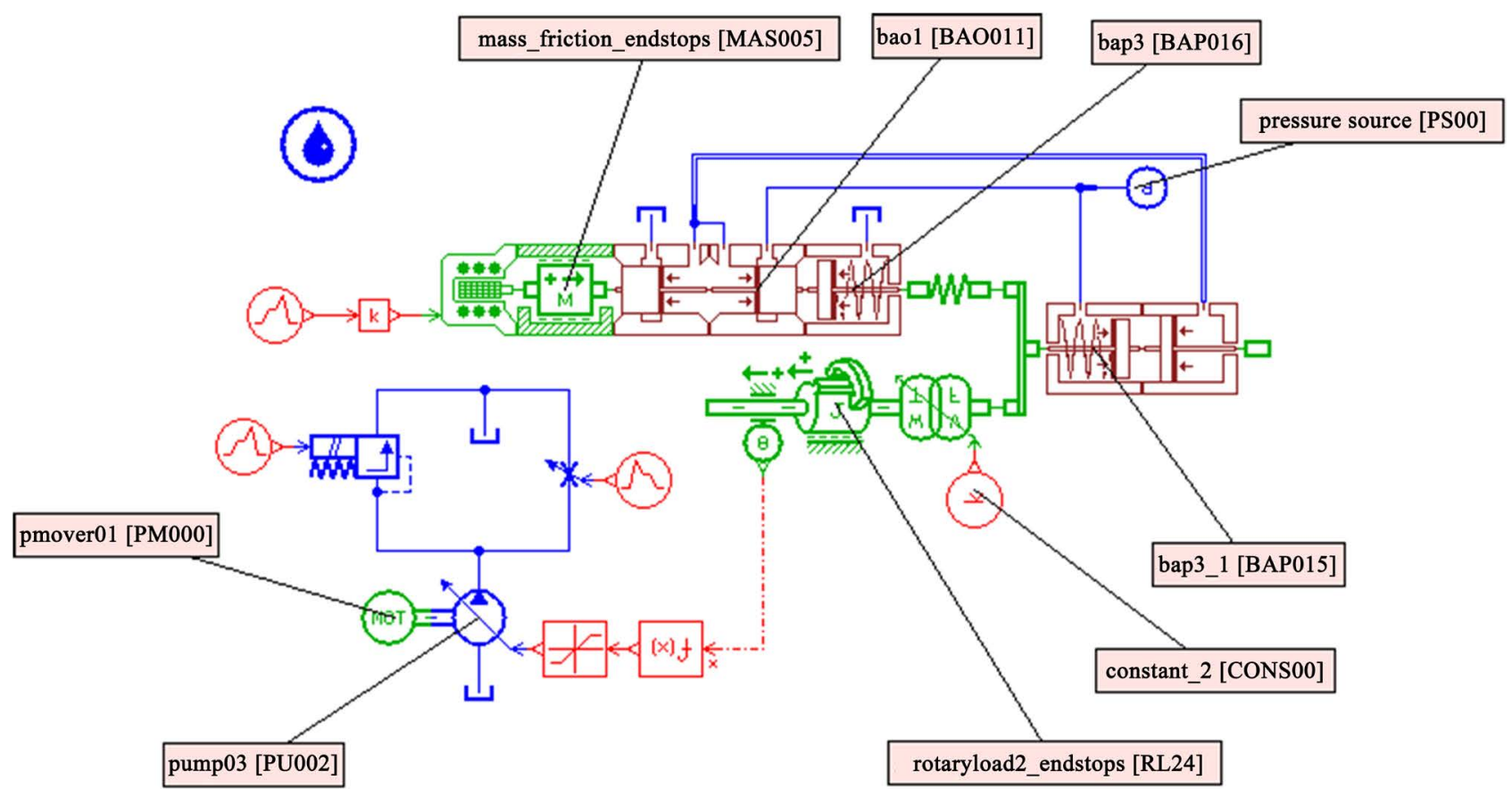

Figure 8. The AMESim simulation model of A4VSO pump.

Table 4. Simulation parameters.

\begin{tabular}{ccc}
\hline Name & Type & Value \\
\hline pmover01 & shaft speed & $1450 \mathrm{r} / \mathrm{min}$ \\
pump03 & pump displacement & $71 \mathrm{~mL} / \mathrm{r}$ \\
rotaryload2_endstops & moment of inertia & $0.01 \mathrm{~kg} \cdot \mathrm{m}^{2}$ \\
constant_2 & coefficient of viscous friction & $2.5 \mathrm{~N} \cdot \mathrm{m}^{-1} / \mathrm{r} \cdot \mathrm{min}^{-1}$ \\
bap3_1 & constant value & $75 \mathrm{~mm}$ \\
pressuresource & piston diameter|rod diameter & $27.2 \mathrm{~mm} / 13.6 \mathrm{~mm}$ \\
bap3 & spring stiffness & $12.78 \mathrm{~N} / \mathrm{mm}$ \\
& pressure at start/end of stage1 & $4 \mathrm{MPa}$ \\
& piston diameter|rod diameter & $10 \mathrm{~mm} / 0 \mathrm{~mm}$ \\
bao1 & spring stiffness & $8 \mathrm{~N} / \mathrm{mm}$ \\
mass_friction_endstops & spring force at zero displacement & $20 \mathrm{~N}$ \\
\hline
\end{tabular}

Aiming at the independent metering control system in this paper, its cosimulation model is established, in which the mechanical-hydraulic part of the model is established in AMESim software and the control part is established in Matlab/Simulink software, as shown in Figure 9 and Figure 10, respectively. SC_1 and SC_4 are the packaging modules of the directional valve of valve group unit; SC_2 is the packaging module of the electric proportional pump; the relationship between the load force outside the hydraulic cylinder and the displacement 
of the piston is imported in the form of a text file; and the diameter of the damping hole is set to $0.4 \mathrm{~mm}$.

Because there are many simulation parameters involved in the model, the assignment of specific parameters can be consulted in document [16].

\subsection{Simulation Result}

For the convenience of description, the proposed independent metering control system is referred to as LSIMC system. The simulation will focus on the analysis of speed control, energy-saving and anti-flow saturation characteristics of LSIMC

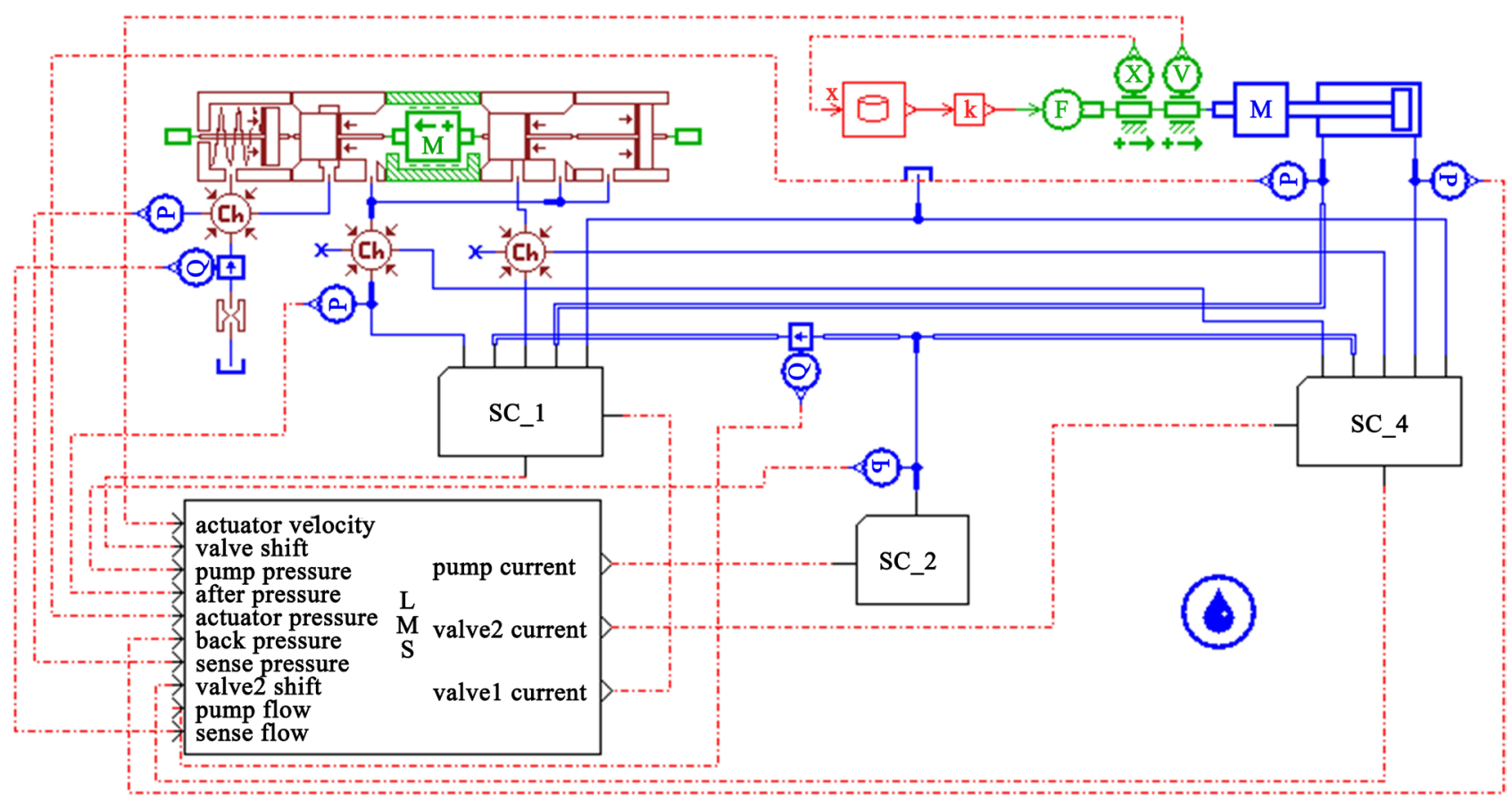

Figure 9. The mechanical-hydraulic model of independent metering control system.

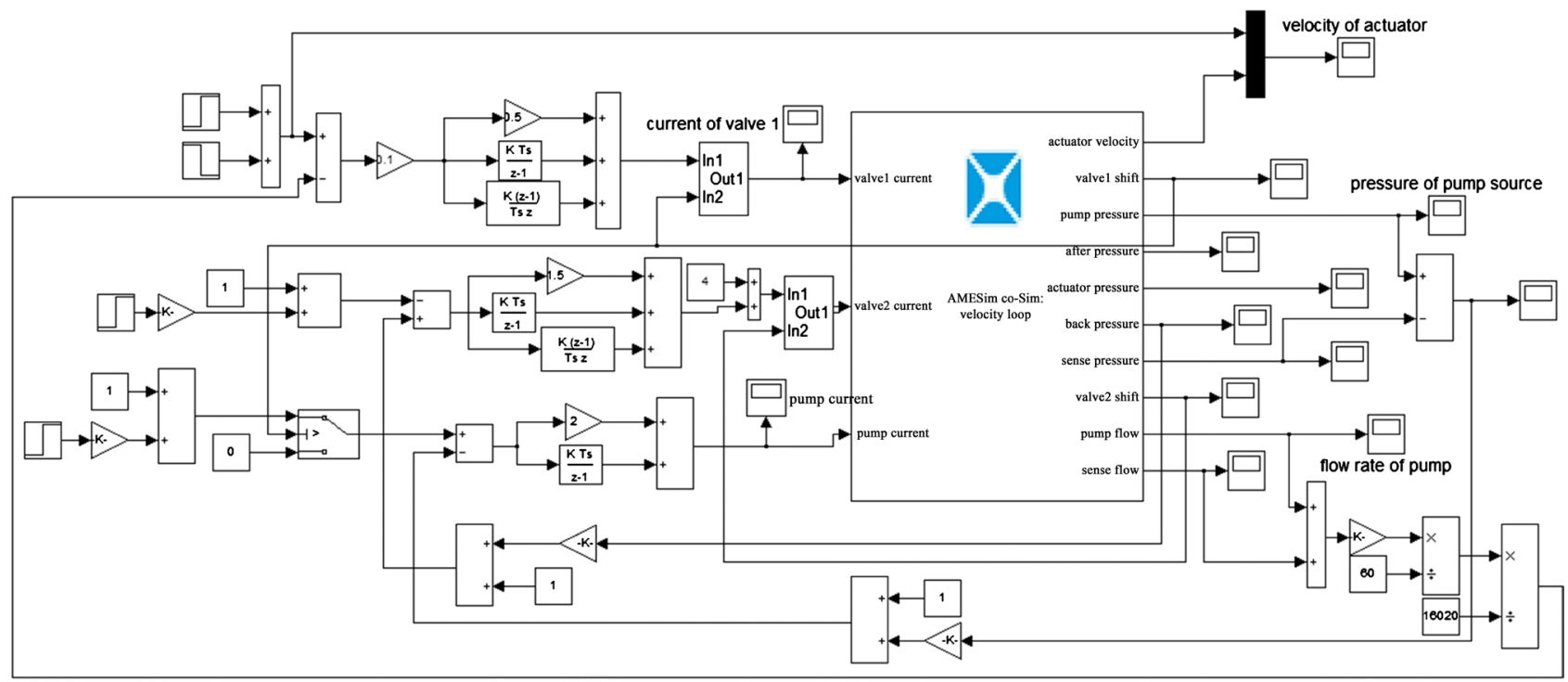

Figure 10. The control model of independent metering control system. 
system.

\subsubsection{Speed Control Characteristic}

As far as the speed control strategy of actuator is concerned, there are two schemes for the independent metering control system at present. One is to use calculated flow feedback control and the other is speed direct detection feedback control. Based on the above simulation models, two corresponding system simulation models are established respectively. The simulation results of the two models are shown in Figure 11 and Figure 12. It can be seen from the figure that the speed control of the hydraulic cylinder has good steady-state accuracy when the external load changes continuously. The two speed control methods mentioned above can achieve relatively stable step response characteristics, and the adjustment time is less than $1 \mathrm{~s}$.

\subsubsection{Energy-Saving Characteristic}

In order to highlight the energy-saving effect of LSIMC, the LSIMC is compared with EHLSS (electronic and hydraulic load-sensing system). The simulation results of the two systems are shown in Figure 13 and Figure 14. It can be seen from the figures that the output flow of the pump source is basically the same because of the same expected speed of the hydraulic cylinder in the system, but the pressure drop of the valve of the outlet circuit is much larger than that of the inlet valve due to the simultaneous throttling of the inlet and outlet groove in the directional valve in the EHLSS system, especially when the hydraulic cylinder is

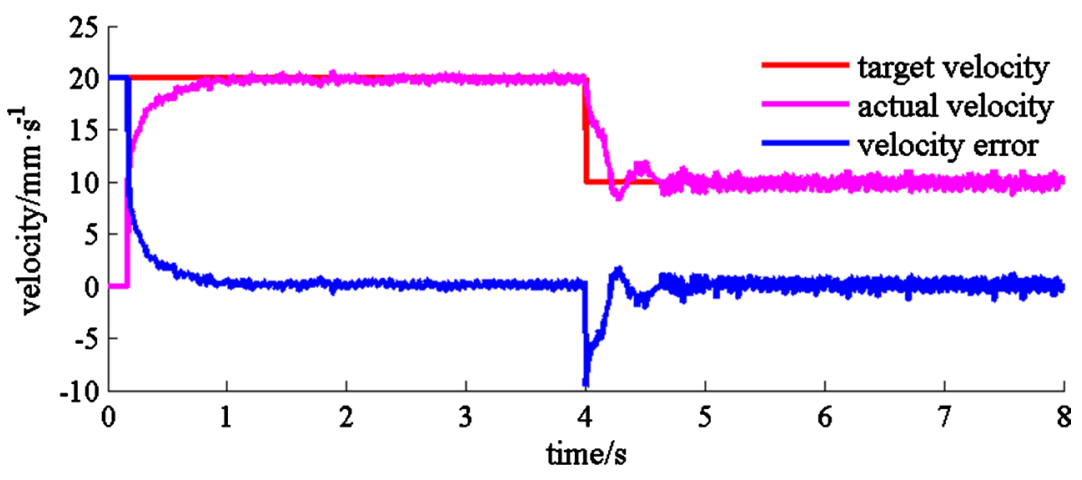

Figure 11. The speed control of actuator based on calculated flow feedback control.

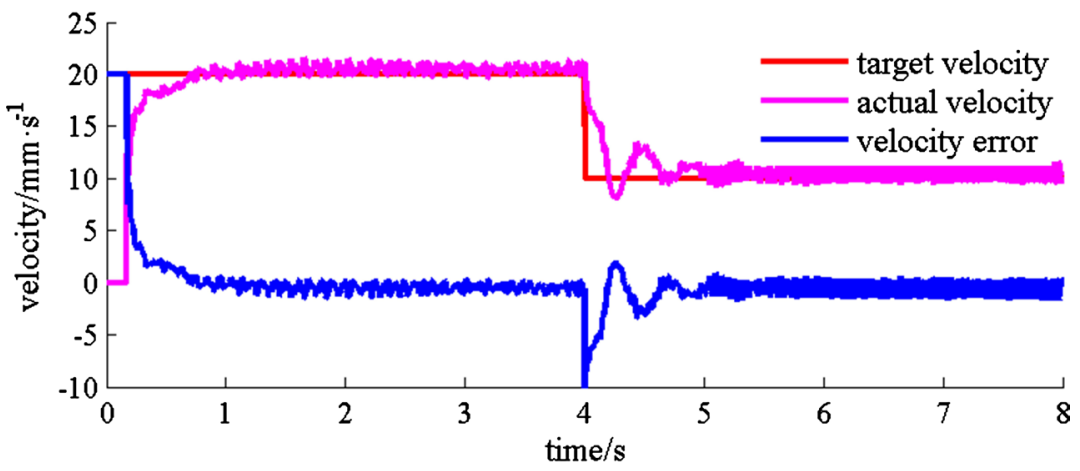

Figure 12. The speed control of actuator based on direct detection feedback control. 


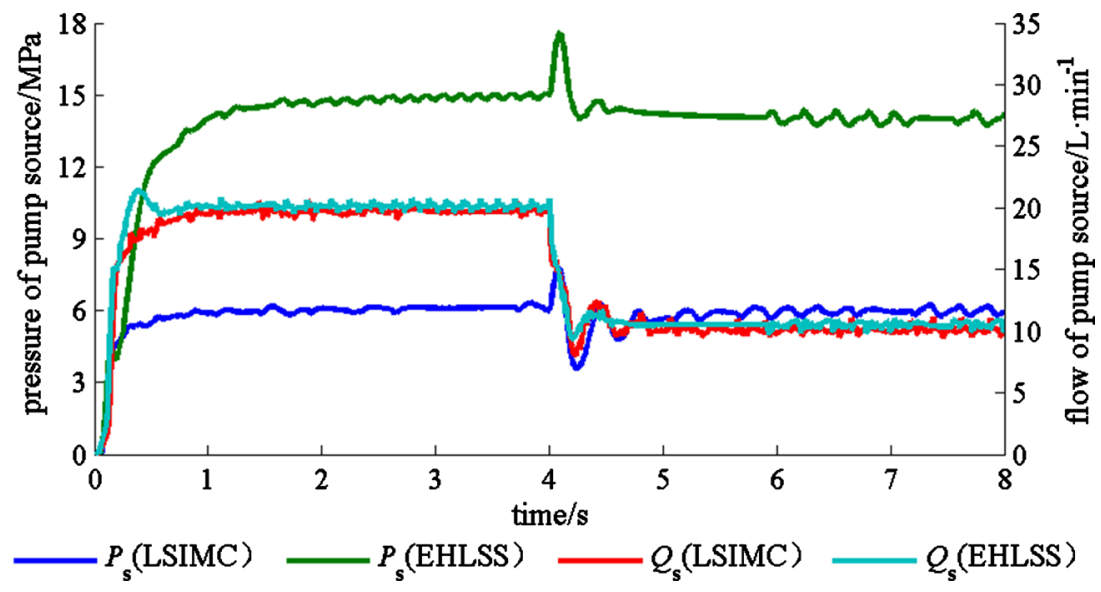

Figure 13. The comparisons of pressure and flow of pump source.
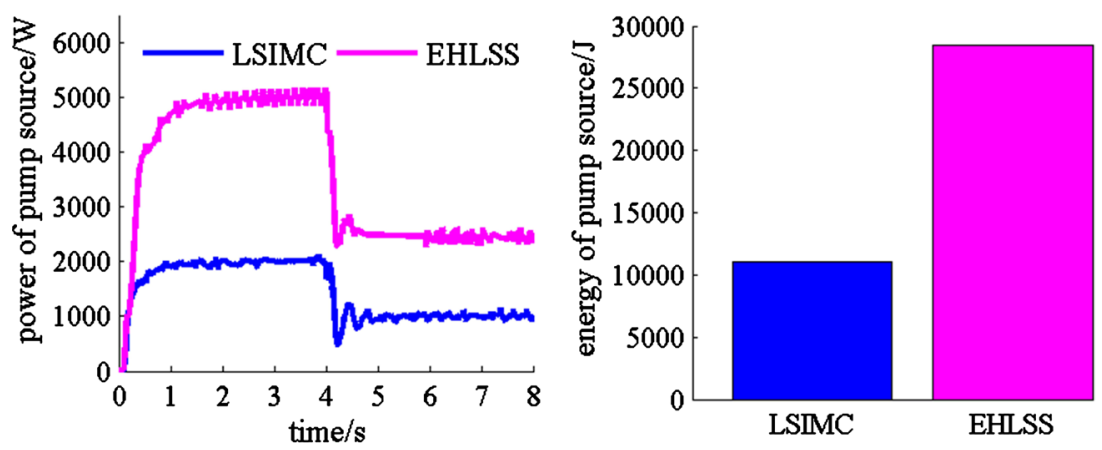

Figure 14. The power and energy consumption of pump source.

blocked and retracted. As a result, the pump pressure and energy consumption of the system are much larger than those of the LSIMC system, and the energy consumption of the LSIMC system is $59 \%$ less than that of the EHLSS system.

\subsubsection{Anti-Flow Saturation Characteristic}

In order to analyze the anti-flow saturation characteristic of LSIMC system, two actuator branches are set up in the model. The load of the second branch is $1 / 5$ of the load of the first branch. The current of the outlet direction valve in the valve group unit is $0.5 \mathrm{~A}$, the inlet direction valve of the heavy load branch feeds a constant current of $0.4 \mathrm{~A}$ within $0-6 \mathrm{~s}$, and the light load branch feeds a constant current of $0.5 \mathrm{~A}$. The given current of the inlet directional valve is $0.4 \mathrm{~A}$ in $0-3 \mathrm{~s}$ and $0.8 \mathrm{~A}$ in $3-6 \mathrm{~s}$. The simulation result is shown in Figure 15. From the figure, it can be seen that in $0-3 \mathrm{~s}$, the control areas of inlet directional valves in the heavy and light branches is equal, and the speed change of hydraulic cylinder is comparatively consistent, but the speed of heavy hydraulic cylinder is slightly lower than that of light hydraulic cylinder. According to the flow curve of pump, the system is in flow saturation state at this time, and the speed deviation is mainly due to the heavy load. Some of the oil in the load branch leaks from the damping hole of the feedback oil circuit. In 3 to 6 seconds, the control area of inlet direction valve in the light branch becomes larger. Due to the role of pressure compensation valve, the flow of heavy and light branch begins to adjust 


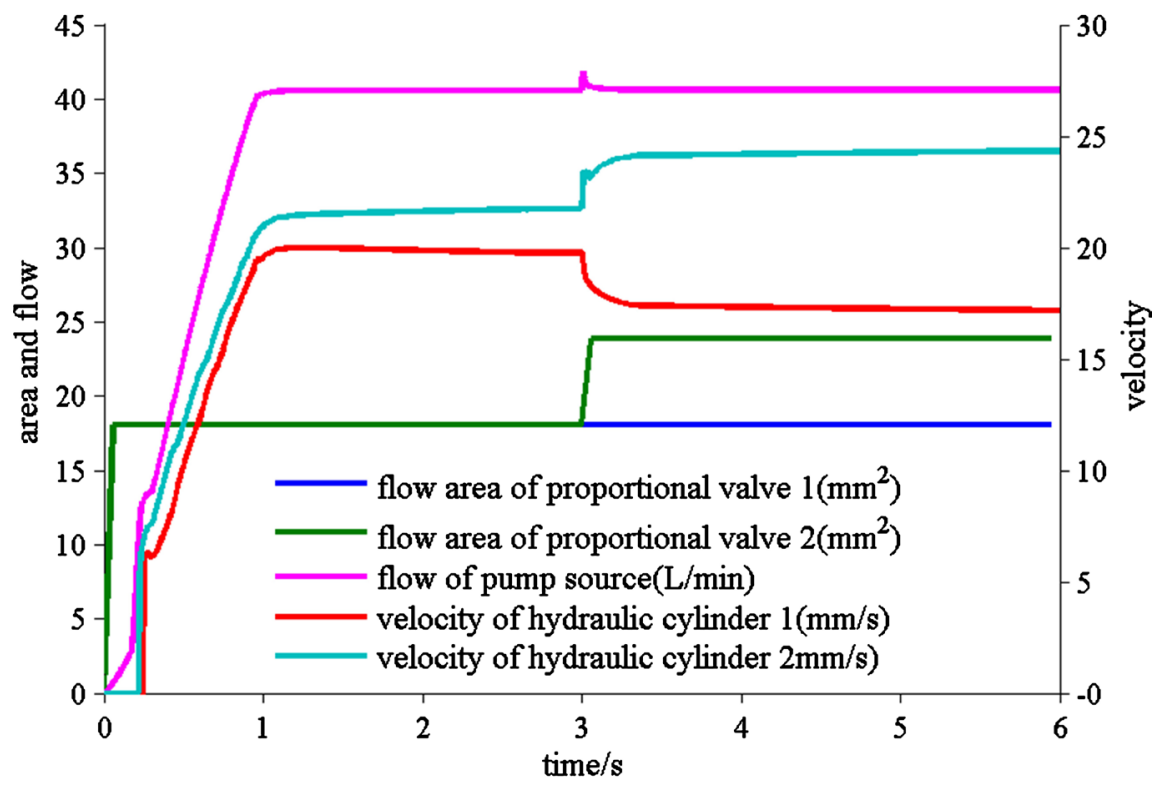

Figure 15. The simulation result of anti-flow saturation.

automatically according to the area ratio of the inlet valve.

\section{Summary}

In this paper, a new type of independent metering control system is proposed. The simulation results show that the system can achieve better speed control effect of the actuator and has good energy-saving performance. Compared with the existing system structure, the system proposed in this paper can also achieve anti-flow saturation function under multi-actuator working condition, which provides a new way to reduce the design cost of independent metering control system. Of course, this paper only simulates the proposed system characteristics, and subsequently we need to build up a test platform to verify the accuracy of the simulation results.

\section{Acknowledgements}

This work is supported by the National Nature Science Foundation of China (Grant No. 51805228).

\section{Conflicts of Interest}

The authors declare no conflicts of interest regarding the publication of this paper.

\section{References}

[1] Jansson, A. and Palmberg, J.O. (1990) Separate Controls of Meter-in and Meter-out Orifices in Mobile Hydraulic Systems. SAE Transactions, No. 3, 1-48.

https://doi.org/10.4271/901583

[2] Yao, B. and Liu, S. (2002) Energy-Saving Control of Hydraulic Systems with Novel Programmable Valves. Proceedings of the 4 th World Congress on Intelligent Con- 
trol and Automation, Shanghai, 10-14 June 2002, 81-91.

[3] Hu, H.B., Zhang, Q. and Andrew, A. (2003) Multi-Function Realization Using an Integrated Programmable E/H Control Valve. Applied Engineering in Agriculture, 19, 283-290.

[4] Hu, H.B. and Zhang, Q. (2002) Realization of Programmable Control Using a Set of Individually Controlled Electro-Hydraulic Valves. International Journal of Fluid Power, 3, 29-34. https://doi.org/10.1080/14399776.2002.10781135

[5] Zhang, G.T., Gao, Y.J., Zhai, C., et al. (2018) Design and Simulation Research for Independent Metering Control Valve. Chinese Hydraulics and Pneumatics, No. 10, 15-21.

[6] Xu, B. (2005) Computational Flow Feedback and Control Method in Hydraulic Elevators. Chinese Journal of Mechanical Engineering, 18, 490-495. https://doi.org/10.3901/CJME.2005.04.490

[7] Liu, Y.J., Xu, B., Zeng, D. and Yang, H.Y. (2010) Strategy for Flow and Pressure Control of Electro Hydraulic Proportional Separate Meter in and Separate Meter out Control System. Transactions of the Chinese Society of Agricultural Machinery, 41, 182-187.

[8] Xu, B., Ding, R.Q. and Zhang, J.H. (2015) Experiment Research on Individual Metering Systems of Mobile Machinery Based on Coordinate Control of Pump and Valves. Journal of Zhejiang University (Engineering Science), 49, 93-101.

[9] Wang, Q.F., Gu, L.Y. and Lu, Y.X. (2001) Research on Principle and Performance of Meter-in, Meter-out Independent Regulated Based on Pressure Decrease Sensing. Chinese Journal of Mechanical Engineering, 37, 22-24.

[10] He, J.L., Wei, D.F., Feng, L.H. and Hu, J.-P. (2011) Control Strategy of Excavator Hydraulic System with Twin Spool Valve. Machine Design and Research, 27, 98-102.

[11] Sthel, M.S., Tostes, J.G.R. and Tavares, J.R. (2013) Current Energy Crisis and Its Economic and Environmental Consequences: Intense Human Cooperation. Natural Science, 5, 244-252. https://doi.org/10.4236/ns.2013.52A036

[12] Aoki, Y., Uehara, K., Hirose, K., et al. (1994) Load Sensing Fluid Power Systems. SAE Trans, No. 103, 139-153. https://doi.org/10.4271/941714

[13] Zahe, B. (1993) Energiesparende Schaliungen hydraulischer Aniriebe mit veranderlichem Versorgungsdruck and ihre Regelung. RWTH Aachen University, Aachen.

[14] Djurovic, M. and Helduser, S. (2004) New Control Strategies for Electrohydraulic Load Sensing. In: The Bath Workshop on Powe Transmission and Motion Control, Bath, 201-210.

[15] Helduser, S. and Djurovic, M. (2005) Control Strategies for Load-Sensing in Mobile Machinery. The Sixth International Conference on Fluid Power Transmission and Control, Hangzhou, 5-8 April 2005, 32-42.

[16] Zhang, G.T. (2019) Study on Independent Metering Control Valve and System. Yanshan Unversity, Qinhuangdao. 